\title{
UNA JARRA ‘RODIA’ EN LA NECRÓPOLIS DE EL MOLAR (SAN FULGENCIO, ALICANTE)
}

\author{
A ‘RHODIAN’ JUG IN THE NECROPOLIS OF EL MOLAR (SAN FULGENCIO, ALICANTE)
}

\author{
RAIMON GRAELLS I FABREGAT \\ Römisch-Germanisches Zentralmuseum \\ graells@rgzm.de \\ http://orcid.org/0000-0002-9057-7510
}

ANGELO BOTTINI

Già soprintendente della Basilicata e Roma

angelo-bottini@alice.it

http://orcid.org/0000-0002-0663-2071

Recepción: 04-04-2017

Aceptación: 18-05-2017

\section{Resumen}

Se presenta una asa de bronce fragmentada procedente de la necrópolis de El Molar. La identificación tipológica como un tipo particular de asa de jarra de tipo 'rodio' permite una serie de reflexiones sobre su forma, su origen en el Mediterráneo oriental y su cronología en la primera mitad del s. VI a.C.

Palabras clave. Importación; vaso metálico; Península Ibérica; orientalizante; Metaponto; Jonia.

\begin{abstract}
The paper presents a fragmented bronze handle from the necropolis of El Molar. The typological identification as an unusual type of 'rhodian' jug allows some reflections on its morphology, its origin in the western Mediterranean area, and its chronology in the first half of the 6th century BC.
\end{abstract}

Key words. Import; Metallic Vessel; Iberian Peninsula; Orientalizing Period; Metaponto; Ionia. 


\section{INTRODUCCIÓN}

A veces basta un fragmento para ver la necesidad de revisar las interpretaciones sobre una clase de objetos. Otras, el estudio de ese fragmento implica cambiar la lectura de su contexto. En cualquier caso es cierto que un objeto no reescribe la historia de un yacimiento, pero hay algunas excepciones que sí tienen esa capacidad, independientemente de si fragmentados o no. Tal es la fragilidad de nuestra disciplina, necesitada de puntos estables (y fiables) para basar sus argumentos y construir sus discursos. Pero justamente a causa de los pocos puntos fijos de que disponemos, tenemos la obligación de revisarlos y corregirlos constantemente. Los objetos no cambian, pero sí el modo como nos aproximamos a ellos, como escribimos sobre ellos y como conseguimos hacer que participen en la reconstrucción histórica, es decir, lo que cambia es nuestra lectura del pasado.

Pongamos por caso el ejemplo de un objeto erróneamente identificado ( $\mathrm{y}$ a esto estamos, lamentablemente, acostumbrados quienes trabajamos con materiales metálicos). Ese error impide la correcta adscripción cronológica, cultural o incluso funcional del objeto y condiciona la lectura de su contexto y de su lógica asociativa. Puestos a suponer, pongamos que el material identificado (incluso si se trata de un fragmento) lleva a dibujar un cuadro que define una serie de relaciones culturales y una cronología determinada. En ese caso, la revisión y corrección de su
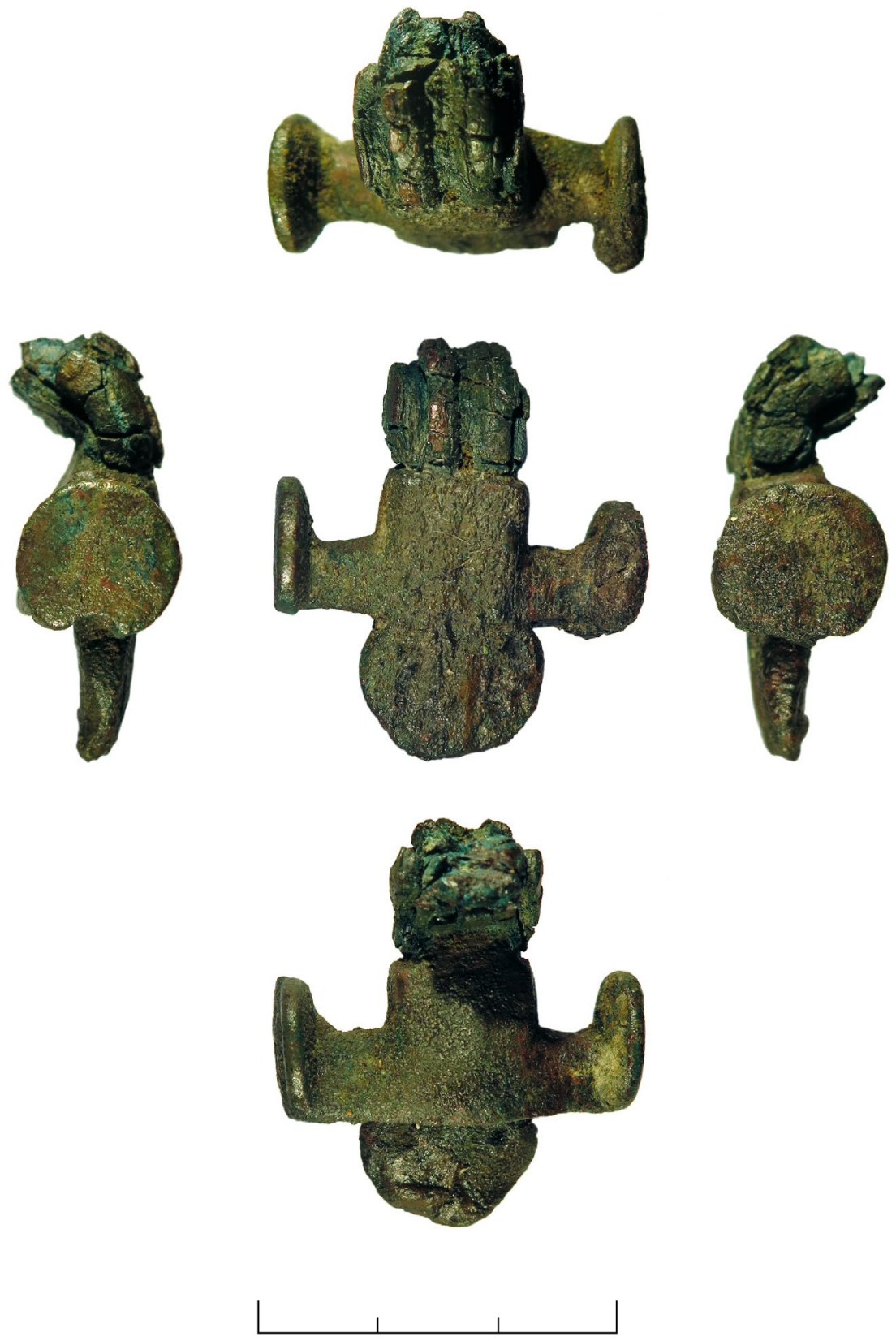

Figura 1: Fragmento de asa del MARQ N. Inv. 5056 procedente de la necrópolis El Molar. Fotografías R. Graells. 
identificación cambia también el cuadro y dibuja una nueva red de relaciones y a veces, incluso, propone cronologías distintas. Estaremos de acuerdo entonces que, para quienes se ocupan del análisis arqueológico e histórico de ese contexto, el cambio es significativo, pues además de implicar la revisión de lo que se haya escrito previamente (cosa que es deseable hacer cada cierto tiempo) abre los ojos a otros problemas y cuestiones que posiblemente enriquecen el debate y facilitan un mayor y mejor conocimiento de lo que se estudia (materiales, contexto o dinámica histórica).

El caso que aquí nos ocupa es uno de estos fragmentos 'problemáticos', uno de aquellos que una vez identificados resuelven problemas y complican discursos. El fragmento de asa recuperado en la necrópolis de El Molar (San Fulgencio, prov. Alicante) se presenta aquí como tal por primera vez y se contextualiza con sus escasos paralelos mediterráneos para evidenciar la presencia de materiales orientalizantes en la necrópolis y abrir así la discusión acerca de la existencia, o no, de una fase orientalizante en la misma.

\section{UN FRAGMENTO DE JARRA DE BRONCE}

El fragmento, inventariado bajo el número 5056 del MARQ (Fig. 1), no aparece en las memorias de las primeras excavaciones en la necrópolis realizadas por J. Lafuente y J. Senent pero ha sido publicado como pieza procedente de la necrópolis por quienes han revisado sus materiales en los últimos años (M. Monraval y A. Peña), quienes han coincidido en interpretarlo como «cierre de gran tamaño... atalaje de un caballo... de difícil atribución» (Monraval, 1992: 92, Nr. 113; Peña, 2003: 98, fig. 29.133). En ambos casos han publicado el dibujo del fragmento con la orientación al revés, es decir, con la parte superior hacia abajo (Fig. 2), lo cual ha dificultado, más si cabe, la correcta lectura del fragmento.

En este contexto, una reflexión sugerida por A. J. Lorrio incide y previene los efectos colaterales de la no publicación de la pieza en los trabajos de quienes excavaron en la necrópolis. Se propone si realmente se trata de una pieza con esa procedencia o si, en realidad se trata de una pieza de otro origen (previsiblemente siempre de la misma área). La pregunta es importante y pone el interrogante sobre la falta de relación con los demás materiales en la necrópolis de San Fulgencio, aunque la certeza de su hallazgo en el área (que encuentra coherencia con los distintos yacimientos de la desembocadura del Segura) no invalida ninguna de las reflexiones que siguen, bien de carácter tipológico, cronológico o sobre su procedencia hispana.

El fragmento es una pieza compleja formada por dos partes claramente diferenciadas:

- Por un lado el soporte o base, caracterizado por dos apéndices laterales de forma discoidal; un apéndice

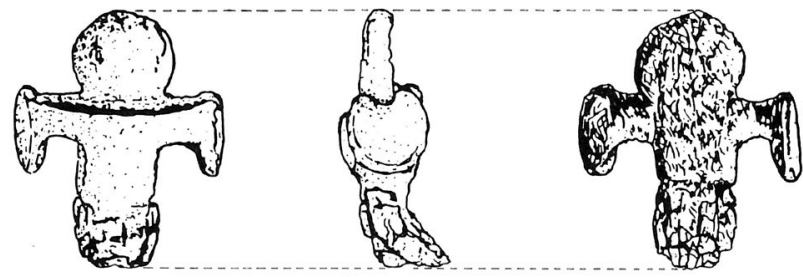

Figura 2: Dibujo del fragmento con orientación invertida, tal y como fue publicado por Monraval (1992: 92, Nr. 113).

discoidal dispuesto hacia abajo que se fijaría al interior del vaso; y el cuerpo, formado a su vez por dos cavidades: la superior para embutir el asa; y la inferior para ser encajada en el borde del vaso.

- Por otro, el asa, fundida en una sola pieza con tres nervios en su lado exterior y embutida en la pieza anterior. Esta parte, con una corrosión distinta que la del fragmento de soporte, muestra una marcada curvatura que corresponde a su morfología sobrelevada, lo cual facilita su reconstrucción.

Las dimensiones son: $38,8 \mathrm{~mm}$ de Altura; $33 \mathrm{~mm}$ de Ancho máximo.

La pieza corresponde al arranque superior de un asa de jarra de bronce de la serie llamada, después de los estudios de B.B. Shefton, 'rodia' (Shefton, 1979). ¿Pero a qué tipo de jarra 'rodia' corresponde?

\section{JARRAS 'RODIAS’: ENÓCOES Y OLPES}

Cuando se habla de jarras metálicas 'rodias' el tipo que se presenta es, por el volumen de ejemplares y su amplia difusión mediterránea, el enócoe. El modelo, por el contrario, deriva de una serie de vasos cerámicos que responden tanto a enócoes como olpes (normalmente panzudos) y se caracterizan por la morfología de sus asas, tocadas en los laterales de su parte (plaqueta o enganche) superior por dos apéndices sobreelevados discoidales.

De este modo, la amplia categoría de jarras de tipo 'rodio' requiere de una atenta observación de las variantes de sus asas, pensadas para cada tipo de vaso. A nivel general, la morfología presenta de manera insalvable una estructura compleja formada por, mínimo, dos piezas:

- una superior, fijada al borde del vaso, formada por dos apéndices discoidales a los lados que sobresalen del borde del vaso, un apéndice discoidal que entra en la pared interna del vaso y sirve como punto de enganche y una parte superior de forma rectangular;

- y una segunda pieza que corresponde al asa, que puede presentarse de sección rectangular o con distinto número de nervios y rematada en su parte inferior con un motivo discoidal, de palmeta o un motivo complejo con otra pieza aplicada (que 

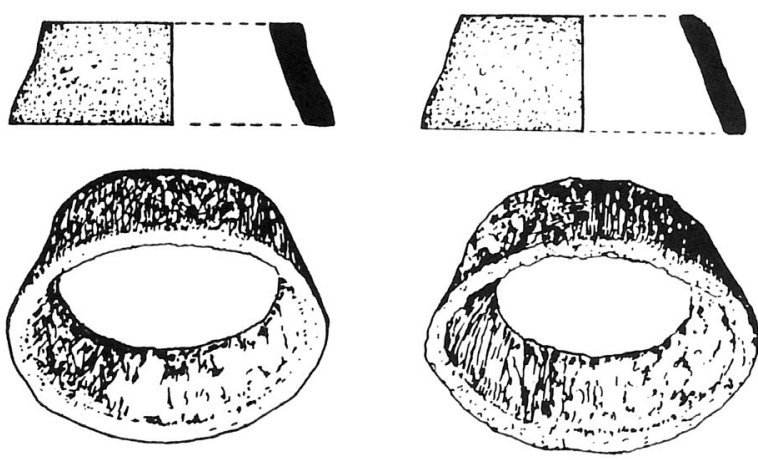

Figura 3: Dibujo de los posibles pies elevados de forma troncocónica en bronce recuperados en la necrópolis de El Molar (MARQ N. Inv. 5056 y 5026). A partir de Monraval, 1992: 99100, Nr. 128-129 (invertida la orientación).

serviría como base y sería la tercera pieza de este elemento), donde se fija al cuerpo del vaso.

A este modelo básico, algunas variantes incorporan apliques decorativos (en relieve o incisos) que se disponen sobre la pared externa de los apéndices discoidales de la parte superior, tanto el interno como los dos laterales.

Decíamos que el catálogo ha considerado normalmente este tipo de asas como propias de una forma particular, el enócoe (Shefton, 1979; Camporeale, 1981; Hiller, 1983; Rolley, 1988; Pare, 1992; Naso, 2003: 61-63, Nr. Cat. 94-98), pero estudios más recientes y, sobretodo, el registro arqueológico de la Italia meridional y la revisión de los vasos metálicos del santuario de Olimpia permiten ampliar el abanico de posibilidades considerando otros vasos como los olpes. En este segundo grupo, la ausencia generalizada de elementos decorativos sobre los apéndices y las dimensiones sustancialmente menores que los enócoes, permiten reconocer mayor correspondencia con el fragmento aquí en estudio.

Las reducidas dimensiones del ejemplar de El Molar, así como la curvatura del encaje para el borde del vaso coinciden con un vaso de dimensiones sustancialmente menores que las de la serie de enócoes. Ello lleva a reconocer como sus mejores paralelos (aunque con algunas diferencias de matiz) un olpe de la tumba 610 de la necrópolis Crucinia en Metaponto (Italia) (Bottini y Vullo, e.p.), el ejemplar B 6449 del santuario de Olimpia (ejemplar inédito, agradecemos la información a B. Schweizer) y un ejemplar descontextualizado del RGZM (O. 26713), adquirido en Italia pero sin contexto preciso (Naso, 2003: 63, Nr. Cat. 97, Tav. 35), todos ellos fechados en la primera mitad del s. VI a.C.

Tomando estos paralelos, todos ellos incompletos, parece difícil poder reconstruir la forma de la jarrita de El Molar, pero si aceptamos el parecido razonable con otro grupo de olpes identificados en Bologna y en otros contextos etruscos (Bottini, e.p.), distintos de los de Metaponto, Molar, Olimpia y RGZM por el tipo de asa, podemos proponer que este tipo de jarritas presentarían un cuerpo esbelto, con la panza baja y el pie formado por otra pieza, siempre de tipo troncocónico.

Casualmente, de la necrópolis de El Molar proceden dos elementos troncocónicos de bronce, posibles pies elevados (Lafuente, 1929: 630; Senent, 1930: Lám. XI.4, XII.6 y XVI; Monraval, 1992: 99-100, Nr.

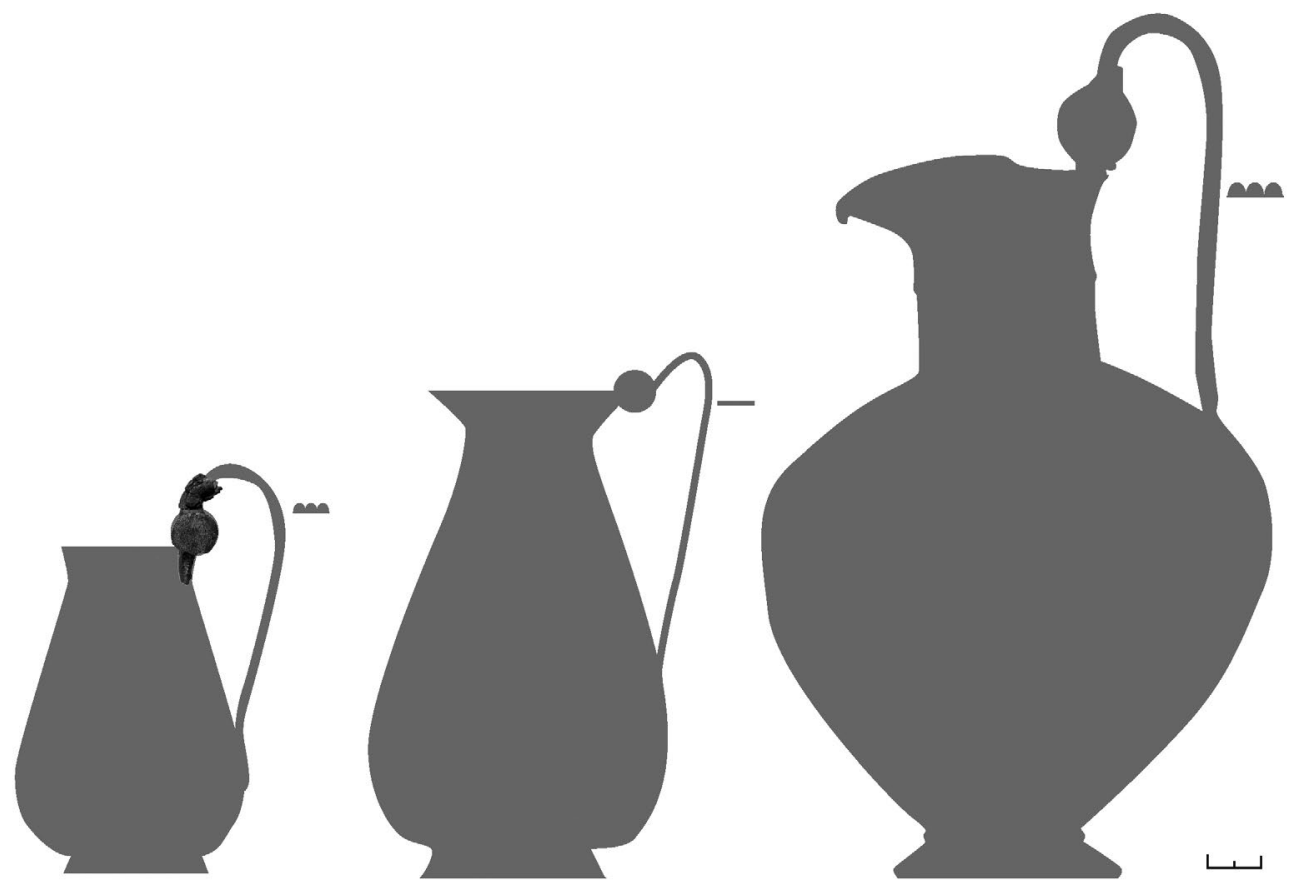

Figura 4: Reconstrucción de la morfología del vaso al que corresponde el fragmento de El Molar y comparación de las dimensiones con un olpe de tipo ‘rodio' etrusco (en el centro) y un enócoe 'rodio' clásico (a la derecha). Dibujo R. Graells. 

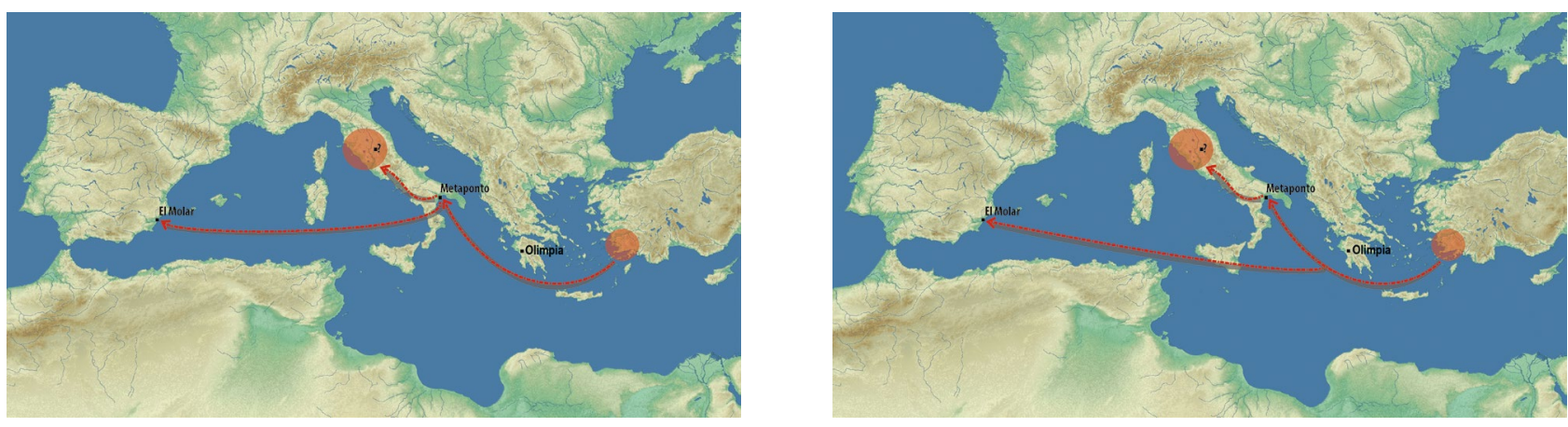

Figura 5: Hipótesis de distribución del modelo de olpe 'rodio': a. Distribución desde la Jonia meridional hacia el sur de Italia y desde allí hacia la Península Ibérica y Etruria; b. Distribución directa desde la Jonia meridional hacia la Península Ibérica e Italia meridional, y desde este último punto hacia Etruria. Dibujo R. Graells.

128-129 -reproducidos de manera invertida creyendo que se trataba de las bocas de los recipientes -; Peña 2003: 92, Nr. 112-113), ambos con dimensiones reducidas coherentes con una jarrita con un asa como la que nos ocupa $(\mathrm{H}$. entre 14,5 y $16 \mathrm{~mm}$; Diám. máx. entre 48 y $49 \mathrm{~mm}$; Diám. mín. entre 37 y $38 \mathrm{~mm}$ ) y que ya Lafuente y luego Monraval interpretaron como posibles bases de jarritas (Fig. 3). Si bien su duplicidad podría aludir a otros objetos de tipología indeterminada, no puede descartarse que una de ellas pudiera haber formado parte de la jarrita. Sea como fuere, la diferencia entre el ejemplar de El Molar y el resto del repertorio de jarras 'rodias' en occidente evidencia su singularidad morfológica (Fig. 4).

Hasta hoy, los ejemplares de tipo 'rodio' conocidos en la Península correspondía exclusivamente a la forma de enócoes, distribuidos en la tumba 5 de la necrópolis de La Joya, Granada y túmulo 2 de Santa Marta, perteneciendo todos al grupo Ba de Shefton y presentando unas dimensiones significativamente grandes dentro de la serie de enócoes 'rodios' (Jiménez-Ávila, 2002: 53-55, 389, Nrs. 14-16, Láms. IX-X)'. Todos ellos, como sucede para la mayoría de estas piezas en el Mediterráneo, depositadas en sus contextos funerarios en un momento próximo al de su uso, no documentándose hasta ahora la tesaurización durante lapsos de tiempo dilatados. Este detalle, como veremos, es importante para considerar el contexto cronológico de la jarrita de El Molar.

Volviendo a la forma, y como anticipábamos, el asa con el dorso decorado con varios nervios no es exclusiva de los vasos en bronce. Es un elemento especialmente frecuente en producciones cerámicas de la segunda mitad del s. VII a.C. de la costa jónica meridional (Kerschner y Schlotzhauer, 2005: 17-39) que presentan también la característica pareja de apéndices discoidales y un perfil sobreelevado. A favor de una cronología alta situada antes del s. VI a.C., parece jugar especialmente la sección de las asas, con tres

1. A ellos se suma el ejemplar de la colección Vives (hoy en la Hispanic Society), ligeramente distinto de los anteriores (Jiménez-Ávila, 2002: 54-55, 389-390, Nr. 17, Láms. XI). nervios en los ejemplares del grupo B y C, mientras que se reducen a dos en el grupo D.

Estas características tipológicas definen un espacio geográfico que coincide con el del origen de las importaciones de lujo documentadas en la necrópolis Crucinia, todas ellas procedentes o del interior de la península anatólica (Bottini, e.p.; Bottini y Vullo, e.p.) o de la costa jónica. Esto demuestra que verosímilmente, desde allí se vehicularon las importaciones anatólicas hacia la Italia meridional (Verger, 2011). De modo que es harto probable que en esa dinámica y contexto jónico deba reconocerse el taller (ya sugerido por B. Bouloumié, 1978: $219 \mathrm{~s}$.) ${ }^{2}$ para este limitado grupo de vasos con asas de tipo 'rodio' exportadas hacia Italia y, como mínimo una vez, hasta la Península Ibérica (Fig. 5).

\section{LA NECRÓPOLIS DE EL MOLAR}

Aunque, como es bien sabido, el interés por el control y ocupación del área de la desembocadura del río Segura en la antigüedad cuenta con inumerables testimonios, especialmente importantes por su dinamismo y riqueza a partir de mediados del s. VII a.C. ${ }^{3}$ Esa zona se conoce particularmente bien en cuanto a los contextos domésticos y funerarios, estos últimos especialmente ricos para el s. V a.C. y momentos sucesivos (síntesis en Uroz Rodríguez y Uroz Sáez, 2010; Mas, Sala y Prados, 2017; passim). Entre los distintos contextos funerarios, el conocido e investigado desde más antiguo es el de la necrópolis de El Molar, a partir de las intervenciones de J. Lafuente de 1929, de J.J. Senent en 1930 (Lafuente, 1929; Senent, 1930; Monraval,

2. Una recopilación del debate tradicional que discutía sobre la producción griega, fenicia o etrusca de estas piezas en Jiménez-Ávila, 2002: 54-55.

3. Intentar una enumeración de los principales trabajos supera los intereses de este artículo, con lo que nos limitamos a citar para las fases antiguas a González-Prats, 2011; 2014 (con bibliografía precedente); y para el arco entre el s. V a.C. y la segunda Guerra Púnica a Abad, Sala y Moratalla, 2017 (con bibliografía precedente). 
1992; Peña, 2003), por la intervención de 1982 que dio con un posible silicernium (Monraval y López, 1984) y con la intervención (aún inédita) realizada en 2008 en el marco de una ampliación de la carretera que corta la necrópolis (López, Soriano y Lara, 2009).

En base a los datos publicados, se acepta hoy que la necrópolis de El Molar se fecha entre finales del s. VI y finales del V a.C. (Peña, 2003: 118) y que debió ser el cementerio del vecino poblado de El Oral (fechado entre finales del s. VI y finales del s. V a.C. según Abad y Sala, 1993: 233-241; Abad y Sala 2009; Abad et al., 2001: 146; Abad et al., 2003; Peña, 2003: 118), aunque la proximidad con el hábitat de La Fonteta (Guardamar del Segura) (síntesis en Rouillard, Gailledrat y Sala, 2007; González Prats, 2011; 2014), en la otra orilla del río, no puede excluir que hubiera sido una necrópolis de aquella ciudad siempre que se documenten materiales y estructuras cronológicamente coherentes con el hábitat.

$\mathrm{Si}$ atendemos a los materiales publicados y dejamos de lado el fragmento que motiva este trabajo, la mayoría de ellos se fecha entre finales del s. VI a.C. y todo el s. V a.C. Los broches de cinturón y las fíbulas así lo indican, situando el broche con decoración de placa de plata aplicada (Graells y Lorrio, 2017: Cat. C Nr.1) como probable pieza metálica más antigua, mientras que el resto de broches de tres garfios, el colgante en forma de paloma o las fíbulas encuentran mejor acómodo en la centuria siguiente. En el s. V a.C., es más probable documentar el aríbalo naucrático, aunque no puede excluirse una cronología ligeramente más alta, en la segunda mitad del s. VI a.C. (Peña, 2003: 73-75, fig. 18.42). Con la misma datación puede analizarse incluso la gran mayoría de la cerámica ática (Peña, 2003: 67-75) de la que sólo un fragmento de Siana Cup (Nordström, 1969: 550; Rouillard, 1991: Inv. 558; Monraval, 1992: 53, Nr. 46; Peña, 2003: 71, fig. 16.52) se podría fechar en la primera mitad del s. VI a.C. (Nordström y Monraval proponen 580-550 a.C., mientras que Rouillard propone 540-520 a.C.) y un fragmento de tapadera de lekanis (Peña, 2003: 7172, fig. 16.52) que se fecharía en la segunda mitad del mismo s. VI a.C.

Lo que sí destaca en esta área funeraria es la ausencia de importaciones fenicias, como podría esperarse si, como se ha sugerido alguna vez, este cementerio hubiera estado relacionado con la colonia/emporio de Fonteta. De hecho, la presencia de materiales orientalizantes o anteriores a mediados del s. VI a.C. son, con el material publicado hasta hoy ${ }^{4}$, prácticamente inexistentes salvo el fragmento que hemos presentado.

4. Caso aparte se observa en la intervención inédita conducida por la empresa Alebus S.L. en 2008 (López, Soriano y Lara, 2009).

\section{CONCLUSIONES}

El cómo llegó el ejemplar de la necrópolis de El Molar a la desembocadura del Segura, seguirá siendo una incógnita a causa de la falta de contexto preciso, pero sin duda el estudio de algunas de las tumbas excavadas en la última década y el mayor conocimiento de las fases orientalizante y arcaica en el entorno, parecen buenas candidatas para comprender su llegada en el marco de unas relaciones con el mediterráneo oriental en un momento antiguo y hacen poco probable que se trate de un objeto llegado en un momento posterior al de su momento de uso.

Si como sucede con los demás vasos de bronce de los contextos orientalizantes hispanos, su depósito en tumba fue sincrónico al de su producción (o ligeramente posterior), este ejemplar abre la cronología de la necrópolis que sube hasta inicios del s. VI a.C. Está claro que los datos aún inéditos de la necrópolis y futuras intervenciones tendrán que contrastar esta propuesta, pues en definitiva supone un interrogante acerca de la correspondencia entre la necrópolis y el hábitat. En caso contrario deberemos considerar si se trata de una pieza amortizada en un contexto más tardío, lo cual, con los datos ahora a disposición no puede excluirse.

La filiación y paralelos de la jarrita amplían el marco de relaciones u orígenes de los bienes adquiridos por los habitantes de la desembocadura del Segura, con lo que este ejemplar contribuye a aumentar, más si cabe, la riqueza, variedad y dinamismo de la cultura material del periodo orientalizante en el área y abre la necesidad de completar el estudio de la necrópolis y su entorno.

\section{AGRADECIMIENTOS}

Queremos agradecer al Dr. M. Olcina (Director del MARQ) las facilidades para estudiar la pieza en febrero de 2017, así mismo hacemos extensivo el agradecimiento al Dr. E. Verdú quien nos atendió durante la consulta, y a la Dra. F. Sala (Universidad Alicante) por su inestimable colaboración para que esta pieza pudiera ser revisada. Un agradecimiento especial va dirigido al Dr. B. Schweizer (Eberhard Karls Universität Tübingen) por compartir con nosotros la información e imágenes del olpe de Olimpia que forma parte de su estudio inédito sobre la vajilla metálica del santuario. Los agradecimientos se hacen extensivos al Prof. Dr. S. Verger (EPHE-ENS, Paris) y al Prof. Dr. A. J. Lorrio (Universidad Alicante) con quienes hemos tenido ocasión de discutir sobre este objeto. 


\section{REFERENCIAS}

Abad, L., Sala, F. y Moratalla, J. (2017). El Bajo Segura hasta la II Guerra Púnica. Nuevas investigaciones. En F. Prados Martínez y F. Sala Sellés (Eds.). Fenicios y púnicos en el área ibérica. VIII Coloquio Internacional del Centro de Estudios Fenicios y Púnicos (pp. 233-256). Alicante: Universidad de Alicante.

Abad, L. et alii (2001). El poblamiento ibérico en el Bajo Segura. El Oral (II) y la Escuera. Bibliotheca Archaeologica Hispana 12. Madrid: Real Academia de la Historia.

Abad, L. et alii (2003). Ancient trade in south-eastern Iberia: the lower Segura river as focus of exchange activities. Ancient West \& East, 2.2, 265-282.

Abad, L. y Sala, F. (1992). Las necrópolis ibéricas del área de Levante. En Congreso de Arqueología Ibérica: las necrópolis (Madrid, 1991) (pp. 145-167). Madrid: Universidad Autónoma de Madrid.

Abad, L. y Sala, F. (1993). El poblado ibérico de El Oral. TV del SIP 90. Valencia: Universidad de Valencia.

Abad, L. y Sala, F. (2009). La arquitectura y el urbanismo en El Oral (San Fulgenci, Alicante). Un ejemplo de asimilación de la arquitectura fenicia y púnica. En S. Hellas y D. Marzoli (Eds.). Phönizisches und punisches Städtewesen, Akten der internationalen Tagung in Rom (21. Bis 23. Februar 2007) (pp. 499-513). Iberia Archaeologica, 13. Mainz am Rhein: von Zabern.

Bottini, A. (e.p.). Italici e greci nella Basilicata meridionale, dalla fondazione di Sibari a quella di Metaponto. AMSMG.

Bottini, A. y Tagliente, M. (1994). Osservazioni sulle importazioni etrusche in area lucana. En Atti del XXXIII convegno internazionale di studi sulla Magna Grecia (Taranto 1993). Magna Grecia, Etruschi, Fenici (pp. 487-528). Taranto: Istituto per la storia e l'archeologia della Magna Grecia.

Bottini, A. y Vullo, M.S. (e.p.). Metaponto: tombe della necropoli occidentale. En Atti del $56^{\circ}$ Convegno Internazionale di Studi Sulla Magna Grecia (Taranto 2016). Tra Bradano e Sinni: Greci e popolazioni locali nell'arco jonico (VIII - V sec. a.C.). Taranto: Istituto per la storia e l'archeologia della Magna Grecia.

Bouloumié, B. (1978). Le tumulus de Pertuis (Vaucluse) et les oenochoés «rhodiennes» hors d'Étrurie. Gallia, 36, 219-241.

Camporeale, G. (1981). Rec. B. Shefton, Die «rhodischen» Bronzekannen, Marburg 1979. ArchCl, 33, 400-405.

Chiesa, F. (1993). Aspetti dell'orientalizzante recente in Campania: la tomba 1 di Cales. Quaderni di Acme 19. Milano: Cisalpino.

González Prats, A. (2011). La Fonteta. Excavaciones de 1996-2002 en la colonia de la actual desembocadura del río Segura (Guardamar del Segura, Alicante). Vol. 1. Seminarios Internacionales sobre Temas Fenicios. Alicante.

González Prats, A. (2014). La Fonteta-2. Estudio de los materiales arqueológicos hallados en la colonia fenicia de la actual desembocadura del rio Segura (Guardamar del Segura, Alicante). Tomo 1. Seminarios Internacionales sobre Temas Fenicios. Alicante.

Graells, R. y Lorrio, A.J. (2017). Problemas de cultura material. Los broches de cinturón de garfios con decoración a molde de la Península Ibérica (s. VII-VI a.C.). Alicante: Universidad de Alicante.

Hiller, H. (1983). Rec. B. Shefton, Die «rhodischen» Bronzekannen, Marburg 1979. BJb, 183, 792-796.

Jiménez-Ávila, J. (2002). La toréutica orientalizante en la Península Ibérica. Bibliotheca Archaeologica Hispana 16 (=Studia Hispano-Phoenicia 2). Madrid: Real Academia de la Historia.

Kerschner, M. y Schlotzhauer, U. (2005). A New Classification System for East Greek Pottery. Ancient West \& East, 4, 1-56.

Lafuente, J. (1929). La necrópolis ibérica de El Molar (provincia de Alicante). Boletín de la Real Academia de Historia, XCIV, 617-632.

López, E., Soriano, S. y Lara, G. (2009). Excavación arqueológica y seguimiento de obra. Rotonda en el PK 74,700 de N-332. Poligono VIII San Fulgencio (Alicante). Memoria de excavaciones inédita. Alicante.

Mas, B., Sala, F. y Prados, F. (2017). Un hipogeo con dromos escalonado de tipología fenicio-púnica en la desembocadura del Segura. En F. Prados Martinez y F. Sala Sellés (Eds.). Fenicios y púnicos en el área ibérica. VIII Coloquio Internacional del Centro de Estudios Fenicios y Púnicos (pp. 329-345). Alicante: Universidad de Alicante.

Monraval, M. (1992). La necrópolis ibérica de El Molar. San Fulgencio-Guardamar del Segura. Alicante: Museo Arqueológico Provincial de Alicante.

Monraval, M. y López, M. (1984). Restos de un silicernio en la necrópolis de El Molar (San Fulgencio-Guardamar del Segura, Alicante). Saguntum, 18, 145-162.

Naso, A. (2003). I bronzi etruschi e italici del RömischGermanisches Zentralmuseum, RGZM-Kataloge 33, Mainz Römisch-Germanischen Zentralmuseums. Bonn: In Kommission bei Habelt.

Nordström, S. (1969). La céramique peinte ibérique de la Province d'Alicante. Stockholm Studies in Classical Archaeology VI. Stockholm: Almqvist \& Wiksell.

Pare, Ch. (1992). Ein zweites Fürstengrab von aspremont«La Motte aux Fées« (Arr. Vesoul, Dép. Haute-Sâone). Untersuchungen zur Späthallstattkultur im französischen Raum. JbRGZM, 36, 411-472.

Peña, A. (2003). La Necrópolis Ibérica de El Molar (San Fulgencio, Alicante). Revisión de las excavaciones realizadas en 1928 y 1929. Villena: Fundación Municipal «José María Soler».

Rolley, C. (1988). Importations méditerranéennes. En Les Princes Celtes et la Méditerranée. Rencontres de l'École du Louvre (93-101). Paris: La Documentation Francaise. 
Rouillard, P. (1991). Les grecs et la Péninsule Ibérique du VIIIe au IVe siècle avant J.-Chr. Publications du Centre Pierre Paris 21. Paris: Diffusion, De Boccard.

Rouillard, P., Gailledrat, E. y Sala, F. (2007). L'établissement protohistorique de La Fonteta (fin VIIIe - fin VIe siècle av. J.-C.). Fouilles de la Rábita de Guardamar II. Collection de la Casa de Velázquez 96. Madrid: Casa de Velázquez.

Senent, J. (1930). Excavaciones en la necrópolis de El Molar. Memoria de la Junta Superior de Excavaciones Arqueológicas 107. Madrid: Tip. de la Revista de Archivos, Bibliotecas y Museos.
Shefton, B.B. (1979). Die «rhodischen» Bronzekannen. Marburger Studien zur Vor- und Frühgeschichte. 2. Mainz: V. Zabern

Uroz Rodríguez, H. y Uroz Sáez, J. (2010). Rito, religión y sociedad de la Guardamar ibérica. La necrópolis de Cabezo Lucero. En Guardamar del Segura. Arqueología y Museo (pp. 90-113). Museos Municipales en el MARQ. Alicante: Museo Arqueológico Provincial de Alicante..

Verger, S. (2011). Les objets métalliques du sanctuaire de Pérachora et la dynamique des échanges entre mers ionienne, adriatique et tyrrhénienne à l'époque archaïque. En G. De Sensi Sestito y M. Intrieri (Coords.), Sulla rotta per la Sicilia: l'Epiro, Corcira e l'Occidente (pp. 19-59). Pisa: ETS. 